East African Medical Journal Vol. 86 (Supplement) December 2009

THE GLIVEC INTERNATIONAL PATIENT ASSISTANCE PROGRAMME: THE NAIROBI EXPERIENCE

G. W. Kiarie, MBChB, Lecturer, Department of Clinical Medicine and Therapeutics, College of Health Sciences, University of Nairobi, P. O. Box 19676-00202, Nairobi, Kenya, N. A. Othieno-Abinya, MBChB, MMed, Associate Professor, Department of Medicine and M. Riyat, MBChB, FRC Path, Department of Pathology, Aga Khan University Hospital, P. O. Box 30270 - 00100, Nairobi, Kenya

Request for reprints to: Dr. G. W. Kiarie, Department of Clinical Medicine and Therapeutics, College of Health Sciences, University of Nairobi, P. O. Box 19676-00202, Nairobi, Kenya

\title{
THE GLIVEC INTERNATIONAL PATIENT ASSISTANCE PROGRAMME: THE NAIROBI EXPERIENCE
}

\author{
G. W. KIARIE, N. A. OTHIENO-ABINYA and M.S. RIYAT
}

\begin{abstract}
SUMMARY
Glivec is a drug used in the treatment of chronic myeloid leukaemia (CML) and gastrointestinal stromal tumours (GISI). It is an expensive drug which would be out of reach for most patients in Kenya. Norvatis Pharmaceutical together with Axios International a healthcare management company and Max Foundation have made it possible for patients in developing countries to get access to the drug at no cost. Patients meet the cost of the confirmatory test and are recruited into the programme to receive the drug at no cost. A total of 201 patients are in the programme in Nairobi, mainly drawn from Kenyatta National Hospital the major referral hospital in Kenya. The age range is nine years to 75 years with a mean age of 39.5 years. Males make up $56.5 \%$ while females are 43.5\%. CML are $173(86 \%)$ while GIST patients are $28(13.9 \%)$. Most of the CML cases are referred in the chronic stable phase $(87.8 \%$ ) and $85.7 \%$ have been on hydroxyurea as the initial treatment. Compliance rates are approximately $80 \%$.
\end{abstract}

\section{INTRODUCTION}

Glivec (imatinib) is a drug used in treatment of patients diagnosed with Philadelphia chromosomepositive chronic myeloid leukaemia (Ph+ CML) or gastrointestinal stromal tumours (GIST). It was approved for use in 2002 and is marketed by the pharmaceutical company Norvatis. Due to the restrictive cost of the drug very few patients in developing countries can get access to use of this drug. (The approximate cost per month for one patient is KShs 400,000 or US \$ 5334). GLIVEC international patient assistance programme(GIPAP) helps patients who are not insured, not reimbursed and who cannot pay for treatment privately and are in developing countries with minimal resource capabilities to access the drug. Glivec global patient access programmes include a range of flexible models including shared donation (charities, government bodies and other payers partner with Norvatis to provide glivec free to patients), full pay (Norvatis pays fully for glivec), or co-pay (Norvatis and the patient share the cost of glivec) models. National and local partnerships are used to implement these Glivec patient access programmes with a goal to provide the best cancer care possible for the greatest number of patients.

Over 34,500 patients in 80 countries who would otherwise, not have been able to afford treatment have benefited from the programme.

Norvatis partners with Axios International a consulting company founded in 1997 that specialises in strategic advice and technical assistance to improve healthcare delivery services in low and middle income countries. Axios' origins go back to the early years of the battle for HIV treatment where people felt that developing countries were 'too poor and too un-educated' to be able to use antiretrovirals (ARVs).Mostopinionleaders maintained that patients in developing countries would not be compliant with ARVs treatment and that giving these patients access to ARVs would be risky, irresponsible and create ARV resistance. Axios pioneered ARV programmes in Cote d' Ivoire, Vietnam, Chile and Uganda that proved that ARV treatment could be done safely and effectively in developing countries and it opened the door for the subsequent price reductions and ARV initiatives for developing countries.

Theother Norvatis partner is the MaxFoundation a US-based non-profit cancer organization with international focus. The Max Foundation honours life of Maximiliano (Max) Rivarola who was diagnosed with chronic myeloid leukaemia (CML) at the age of 14 years and lived with outstanding courage until 17 years of age. The Foundation's focus has been to 
help patients diagnosed with blood and rare cancers by facilitating access to treatment and providing care and support for those who have limited access to resources.

\section{CASE STUDY}

The GIPAP started in Kenya in 2002 in two centres; the NairobiHospitaland the Aga KhanUniversity Hospital. The operational team involved in GIPAP includes five doctors, two pharmacists, other two health care workers. Three consultants volunteer their services, while the Nairobi Hospital offers the administrative frame work by providing a secretary, the pharmacists, a medical officer and also space to run the clinic every two weeks; at no charge to the patient.

Majority of the patients seen are drawn from Kenyatta National Hospital where they are usually referred from peripheral centres for management of their cancers. The preliminary diagnosis often has been made at the primary health care facilities ; CML patients will have a diagnostic bone marrow aspirate while GIST patients a biopsy histopathology report.

The entry point into the programme is for the CML patients to get a Philadelphia chromosome test (cytogenetic defect: $\mathrm{t}(\mathrm{q} ; 22)(\mathrm{q} 34 ; \mathrm{q} 11)$ ) or ABL / BCR positive FISH test. The patient meets the cost of this test which is approximately kshs 18,000 or US $\$ 240$. The GIST patients are required to do a confirmatory CD 117 immunophenotyping or platelet derived growth factor receptor (PDGFR), TK mutation testing which costs approximately kshs $6,000 \mathrm{kshs}$ or US $\$ 80$. For some patients this is impossible. Many of the patients sell off some property or call for contributions from their communities or extended families to carry out the test due to the promise of more effective free life -long better treatment thereafter.

The application is done under one of the three GIPAP consultants and data on patients' epidemiological details, stage of disease and history of previous treatments is input and emailed to the Axios International Coordinator. A response takes 24 to 48 hours and patients get an individual GIPAP number.

All patients are commenced on glivec $400 \mathrm{mg}$ once a day and an initial prescription for a month is given with a clinic date for review. At this outpatient visit a clinical assessment for response and toxicities is done and blood test results are reviewed. Dose adjustments are made accordingly. Patients with co-morbidities are advised to adhere to their other specialist clinics. When patients require other specialist reviews they are referred to their primary referral facilities or to Kenyatta National Hospital.

On a regular basis patients are reassessed for reapproval to continue on glivec. The current dosing, toxicities and other outcomes are updated.
The Nairobi GIPAP: The programme started in Nairobi in 2002 and by November 2009, 201 patients were receiving glivec free of charge in the programme. CML patients make up 173 (86\%) males and 28 (13.9\%) females of the patients on treatment.

Male patients are $113(56.5 \%)$ and female patients were $88(40.4 \%)$. The age distribution is nine years to 75 years. Most of the patient come from Central province with $81 \%$ being Kikuyus, Luo $17(9.1 \%$ ) and Luhya $11(5.9 \%)$. This is thought to be due to catchment area of Kenyatta National Hospital which is the main source of patients. For the CML patients $87.8 \%$ of patients are referred at the chronic stable phase. Hydroxyurea is the drug commonly previously prescribed in up to $85.7 \%$ of CML cases. Compliance rates are wellover $80 \%$ mainly due to the motivation of improvement noted by the patient. The patients came up with a patient support group which is involved in counselling and creating awareness about the two conditions. They aim to increase referrals to the clinic so that more deserving patients benefit from the treatment

Challenges of the programme: The programme offers access to glivec for a very small proportion of patients with CML and GIST in Kenya. This is mainly due to lack of awareness by clinicians and the public even in Nairobi. The tests required as an entry point into the programme are not available in Kenya and the blood samples are sent abroad which is the main reason it is unaffordable to many patients. Some patients lack resources to travel for clinic appointments or to pick up their drugs and they are also unable to carry out the blood tests for comprehensive follow-up. Some patients have developed resistance to glivec and the tests required for application to receive second line treatment with nilotinib are quite restrictive in cost. This process also takes a long time. The biggest worry of course is the sustainability of the "full pay" model where Norvatis supports the total cost of the drug.

\section{CONCLUSION}

As we celebrate the achievements of Professor Edward George Kasili, there is the realisation of the long journey ahead. The Glivec International Patient Assistance Programme has saved the lives of many patients. As welookinto ways of increasing awareness and referrals so that more patients may benefit, we should also find ways of supporting the investigations needed before treatment. Other partners including government may be needed to sustain treatment to bigger numbers of patients. ARV success story gives us hope. Cancer management is costly sometimes without a promise of longevity, but this may be the path to follow other malignancies as well. 